\title{
Micro-Scale Modeling of an Anode-Supported Planar Solid Oxide Fuel Cell
}

P. Chinda ${ }^{1}$, W. Wechsatol ${ }^{1}$, S. Chanchaona ${ }^{1}$, and P. Brault ${ }^{2} *$

\author{
${ }^{1}$ Department of Mechanical Engineering, King Mongkut's University of Technology Thonburi, 126 Pracha-utid \\ Road, Bangmod, Thungkru, Bangkok, 10140, Thailand \\ ${ }^{2}$ Groupe de Recherche sur l'énergétique des Milieux Ionisés (GREMI), UMR 6606 CNRS-Université d'Orléans, \\ BP6744, 45067, Orléans Cedex 2, France
}

[*] Corresponding Author, pascal.brault@univ-orleans.fr

\begin{abstract}
A micro - scale model of a Solid Oxide Fuel Cell (SOFC) involving the mass transfer together with the electrochemical reaction, the transportation of electrons and ions through the respective spherical - shaped electron - conducting and ion - conducting particles inside the electrodes was mathematically developed. Couples of useful parameters were introduced in order to represent the characteristics of the cell. The predicted cell performance was showed according to various operating and design conditions. The effects of micro scale electrode geometry on the cell performance were also taken into account. Parametric study according to the volumetric fraction of ionic and electronic conducting particles was conducted in order to examine the effects of operating conditions on the cell overpotentials. The study results substantiate the fact that SOFC overpotential could be effectively decreased by increasing the operating temperature as well as operating pressure. This present study reveals the working mechanisms of SOFC at the micro - scale level, while demonstrating the use of micro - scale relations to enhance the SOFC performance. The accuracy of the presented model was validated by comparing with already existing experimental results from the available literatures.
\end{abstract}

Keywords: Solid Oxide Fuel Cells, Micro - Scale Model, Mass Transfer, Electrochemical Reaction, Micro Scale Geometry, Spherical - Shaped Particles, Parametric Study 


\section{Macroscopic Approach to Alternative Microscopic Modeling}

The solid oxide fuel cell (SOFC) is a highly efficient energy conversion system that transforms chemical energy to electrical energy and heat directly from gasified fuels by electrochemical reactions of fuels and oxidants. The supplied fuels can be hydrocarbon compounds such as $\mathrm{CH}_{4}, \mathrm{C}_{2} \mathrm{H}_{6}$ and $\mathrm{C}_{3} \mathrm{H}_{8}$, as well as $\mathrm{CO}$ beside $\mathrm{H}_{2}$. The SOFC can be applied to versatile power generation systems, either stationary power generators or auxiliary power sources in automobiles, in aircrafts or even in residential applications [1,2]. Many researchers have been focusing on developing the SOFC fabrication techniques, and new materials to make the SOFC possible commercial applications. Ramakrishna et al. [3] performed numerical analyses of a SOFC on a CFD ACE package and proposed an innovative thin - walled geometry to improve the power density of the cell. Recently, a novel 3-D SOFC was developed by Koh et al. [4] to increase the volumetric power density by increasing the volumetric surface areas of the electrodes. Yang et al. [5] and Hwang et al. [6,7] developed a numerical model to investigate the characteristics of a mono - block - layer built SOFC (MOLB - SOFC), and found that the MOLB - SOFC provides higher fuel/oxidant utilization than the planar type SOFC. The high utilization of the fuel and oxidant reflects the high current generated by the SOFC. However, the current density distributions are less uniform in MOLB - SOFC, which is a significant disadvantage. The major limitation of SOFC usage is their high operating temperature. Intermediate temperature SOFCs and low temperature SOFCs become the subject of interest to lower the operating temperature as well as the material cost of SOFCs. The techniques of thin electrolyte and electrode coating involving new materials have made the creation of intermediate and low temperature SOFCs possible. Yttria - Stabilized Zirconia (YSZ), which is normally used to produce cell electrolytes operating at high temperatures, can still be used in intermediate and low temperature SOFCs. Many studies on Ceria as a possible material for fabricating electrolyte are widely conducted by many researchers [8 -11]. The thin film deposition, a technique widely used for decades in fabrication of Proton Exchange Membrane Fuel Cells (PEMFCs) [12] is now applied in SOFC fabrication [13 - 15]. One of the main advantages of such a thin film fuel cell is that its ohmic resistance is low enough to maintain its high performance at low operating temperature.

In an analysis of the SOFC system, computer simulation based on theoretical modeling is known to be an efficient method to predict the cell, stack or system performance. Mathematical models that predict performance can aid in understanding and development of SOFCs. A mathematical simulation of a SOFC is helpful in examining issues such as temperatures, materials, geometries, dimensions, fuels, and fuel reformation and in determining their associated performance characteristics. When physical properties or reaction kinetics are not 
known reliably, they can be estimated by fitting performance data on small sizes, laboratory scale cells to a mathematical model. Thus, modeling is an important tool in design optimization, helping to answer important practical questions such as what air and fuel flow rates must be used to avoid excessive temperature or pressure drop. On the other hand, by providing answers to questions such as how much the electrical properties of the cell materials must be improved, simulations at the cell and electrode level or the macroscopic level and microscopic level modeling can guide to development of new and improved SOFCs's materials. Mathematical simulation, therefore, has the potential to guide technology development, test the significance of various design features, asses the effectiveness of developments in materials of fabrication procedures, and select optimum operating conditions from a set of feasible parameters. Various modeling approaches exist. The modeling may focus on individual thermal- mechanical, flow, chemical, and electrochemical subsystems or on coupled integrated systems. Because the subsystems are typically characterized by different length scales, modeling may also take place on different levels, ranging from the system level modeling, the cell stack level modeling and the single cell level modeling.

The viewpoint of single cell level modeling is divided into two levels those are macroscopic modeling and microscopic modeling. The macroscopic are first examined from the viewpoint of fluid and mass transport whether heat transfer phenomena that can be obtained understanding of theses transport phenomena in the cell. The effects of porosity on reactant concentration and ohmic overpotentials could also be considered in the macroscopic modeling. The macroscopic appearances of electrodes such as tortuosity and porosity are also related to the microscopic arrangement of electrode particles. However, the activation overpotential was being treated as a property independent of the porosity, while the electrochemical reactions was assumed to occur merely at the interface between electrode and electrolyte layers. Thus macroscopic modeling can hardly predict the effects of electrode structure on the chemical reaction within SOFCs so, it is insufficient to investigate precisely the micro-structural effects. Another level model is the microscopic modeling, which is considered inside the electrodes. Influence of the electrode structures on the electrochemical reaction at the three phase boundary (TPB) has recently been included in microscopic modeling. The microscopic modeling has been simulated and applied to SOFC in recent years and has offered possibilities to enhance the SOFC performance [16-20]. In literatures for microscopic modeling, the properties of porous electrodes and their effects on SOFC performance have been investigated from different aspects.

Costamagna et al. [16] developed a theoretical microscopic model for the evaluation of the performance of an electrode formed by a mixture of electronic conductor and ionic conductor with the spherical particles shape. The results of the mode1 show that the effects of morphology, i.e. the volumetric composition of the electrode 
and the dimensions of the particles, strongly influence the electrode resistance. The model has been applied to EDB/Pt and YSZ/LSM cathodes and YSZ/Ni anodes. Chen et al. [17] developed a mechanistic model for oxygen reduction at YSZ/LSM interface, a complete micro-model for YSZ/LSM composite cathode considering all forms of overpotential was developed which established the interrelationship among the transport phenomena, electrochemical processes and the microstructure of the composite cathode. The exchange current densities of the rate-limiting steps used in the simulation and the model can be used as a tool to guide the design of high performance cathodes. Deseure et al. [18] developed a microscopic model for a composite cathode similar to Chen et al. [17]. Simulation was conducted to predict the optimal design parameters, e.g. cathode thickness, particle size, particle size ratio and YSZ volume fraction, for a LSM/YSZ composite cathode. Hussain et al. [19] considered a 1-D anode-supported planar SOFC with thin layer reaction zone in the vicinity of electrolyte. Their numerical results shown that the increase of either porosity or tortuosity of electrodes leads to worse cell performance, while better cell performance is obtained when the volume fraction of electronic conducting particles is approximately equal to that of ionic conducting particles in reaction zone. Recently they extended their investigation to the cell design with two distinct layers of anode electrode, e.g., reaction layer and backing layer. Ni et al. [20] developed a mathematical model for modeling the performance of solid oxide fuel cell (SOFC) with functionally graded electrodes at the micro-scale level. The model considered all forms of overpotentials and was able to capture the coupled electrochemical reactions and mass transfer involved in the SOFC operation. Additional modeling analyses were conducted to gain better understanding of the SOFC working mechanisms at the micro-scale level and to quantify the performance of micro-structurally graded SOFC. It was found that micro-structural grading could significantly enhance the gas transport but had negligible effects on the ohmic and activation overpotentials, especially for thick electrodes.

Unlike other previous researches, the effect of electrodes' microscopic geometry on the cell performance of an anode - supported Solid Oxide Fuel Cell is included in this microscopic scale model. For example, porosity and tortuosity are parameters that depend on the shape and size of electrode particles. In this study, the microscopic model of an SOFC porous electrode that formed by mixture of electronic conductor and ionic conductor was developed. The model is modeled with spherical particles electrode and takes into account electronic, ionic, and gas transport together with the electrochemical reaction. The forms of overpotentials losses are considered aims to optimize the SOFC performance by optimizing the microstructure relations of SOFC electrode by microscopic scale modeling base on the random packing sphere model [16].

\section{Model Development}


A microscopic scale model of a Solid Oxide Fuel Cell (SOFC) involving electrochemical reactions and mass transport behaviors throughout electrodes packed with spherical-shaped particles was mathematically developed. The model was validated by comparing the predicted results with already available experimental results. By minimizing the cell overpotentials, the model provides the optimal value of the electrode parameters. The present study reveals the working mechanisms of SOFC at the micro-scale level, while demonstrating the use of microstructure relations to enhance the SOFC performance. The processes to modeling can be explained below:

\subsection{The Cell Geometry and the Model Assumptions}

\subsubsection{The Cell Geometry}

An illustration of physical domain of a SOFC is shown in figure 1. Part (a) in figure 1 shows a structure of a unit cell with multiple flow channels, whereas part (b) in figure 1 shows the cross-sectional representation of a composite anode and also part (c) in figure 1 shows the cross - sectional representation of a composite cathode. The computational domain for anode is shown by part (b) in figure 1, which includes the land portion of the interconnect (current collector) interfacing the anode, the porous portion of the anode interfacing the flow channel, the anode and another is interface to an electrolyte. The computational domain for cathode is shown by part and (c) in figure 1, which includes the land portion of the interconnect (current collector) interfacing the cathode, the porous portion of the cathode interfacing the flow channel, the cathode and another is interface to an electrolyte. The electrolyte was made of Yttria - Stabilized Zirconia (YSZ).

From the part (b) in figure 1, the light gray spherical particles represent the ionic conducting particles that in this case are YSZ (Yttria - Stabilized Zirconia) and the dark gray spherical particles represent the electronic conducting particles that in this case is Nickel (Ni) contain inside the anode, respectively. The parameter $\mathrm{N}_{\mathrm{i}}$ represents the rate of mass transport (or denotes as the molar flux of each species, $\mathrm{mol} \mathrm{m}^{-2} \mathrm{~s}^{-1}$ ) both of reactant $\left(\mathrm{H}_{2}\right)$ flow from the channel to the reaction sites of the anode and product $\left(\mathrm{H}_{2} \mathrm{O}\right)$ flow remove from the reaction sites to the channel. In this study the transport of $\mathrm{N}_{\mathrm{i}}$ vary only in the vertical direction or in the direction $\mathrm{x}$ which is shown in the figure 1 (b) not vary in the horizontal direction or the direction y in figure 1 (b). The parameter $\mathrm{x}_{\mathrm{a}}$ represents the anode distance which $\mathrm{x}_{\mathrm{a}}=0$ means the position at the interface between the anode and flow channel and at $\mathrm{x}_{\mathrm{a}}=\mathrm{t}_{\mathrm{an}}$ means the position at the interface between anode and electrolyte. In the similar manner, from the part (c) in figure 1, the light gray spherical particles represent the ionic conducting particles that in this case are YSZ (Yttria - Stabilized Zirconia) and the dark gray spherical particles represent the electronic conducting particles that in this case is LSM (Strontium - doped Lanthanum Manganite) contain inside the 
cathode, respectively. The parameter $\mathrm{N}_{\mathrm{i}}$ represents the molar flux of oxidant or oxygen species $\left(\mathrm{mol} \mathrm{m}^{-2} \mathrm{~s}^{-1}\right)$ flow from the channel to the reaction sites of the cathode. In this study the transport of $\mathrm{N}_{\mathrm{i}}$ vary only in the vertical direction or in the direction $\mathrm{x}$ which is shown in the figure 1(c) not vary in the horizontal direction or the direction $\mathrm{y}$ in figure 1 (c) same as the anode side. The parameter $\mathrm{x}_{\mathrm{c}}$ represents the cathode distance which $\mathrm{x}_{\mathrm{c}}=0$ means the position at the interface between the cathode and flow channel and at $\mathrm{x}_{\mathrm{c}}=\mathrm{t}_{\mathrm{cat}}$ means the position at the interface between cathode and electrolyte.

\subsubsection{The Model Assumptions}

This model is considered only one cell. The packed spherical shaped particles inside the electrodes create the void space, the tortuous flow paths and the interfacial surface between ionic and electronic conducting particles. The cell is assumed to operate under steady state, and to assume that the parameters vary only in the vertical direction. Temperature and total pressure is assumed to be uniform throughout the entire electrode. The total pressure gradient inside the electrode is assumed to be negligible. The convective flux is negligible in the porous anode when compared to the diffusive flux of gaseous species. This implies that the primary mode of specie transport within the porous anode is by diffusion. The mass transfer process inside the porous electrode is by means of diffusion was also selected by the recommendation in the literatures [21 - 23]. Suwanwarangkul et al [21] were concluded that the Dusty - Gas Model (DGM) is the most appropriate model to simulate gas transport phenomena inside a SOFC electrode. The mass flux of species i can be determined by Dusty Gas Model (DGM) that is considered both Knudsen diffusion and Molecular diffusion. The fuel or the anodic reactant is the humidified with $\mathrm{H}_{2} 0.95$ mole fraction and $\mathrm{H}_{2} \mathrm{O} 0.05$ mole fraction. The oxidant or the cathodic reactant is air with $\mathrm{O}_{2}$ and $\mathrm{N}_{2}$ the mole fraction of 0.21 and 0.79 , respectfully. All gases involved in electrochemical reaction behave like an ideal gas, the Soret, Dofour and gravity effects are negligible. The model is negligible the momentum effect in the electrode. The electrode is a composite porous structure, it is modeled based on the assumption that the composite electrode is represented by the particles of electron and ion conducting particles packed together in random and disregards the actual geometric details of the individual particles, so and according to Costamagna et al. [16] for modeling the electrode with random stacks of nearly spherical shaped particles. The each phase of electrode is considered to be homogeneous.

\subsection{Cell Performance and Cell Geometry Relation}


Porous composite electrodes are commonly used in fuel cells due to their extended zone for electrochemical reactions, thus improving the current output of an electrode. The performance of a porous electrode depends on, but is not limited to: (1) the activity of electro catalysts, (2) the specific surface area $\left(\mathrm{m}^{2} \mathrm{~m}^{-3}\right)$ available for electrochemical reaction, (3) the mass transport phenomena, and (4) the ionic and electron conductivity. Because of the complex nature, a detailed simulation technique was employed to predict cell performance under various operating conditions. The present model aims to study the effect of electrodes' microscopic geometry on the cell performance of an anode - supported Solid Oxide Fuel Cell and the parametric study according to the volumetric fraction of ionic and electronic conducting particles was conducted in order to examine the effects of operating conditions on the cell performance. For simulation with the microscopic scale modeling in this work the model considered on mass transport, electrode electrochemical reactions and charge transport. The details on the modeling are described below as follow by starting on considered with the anode side, cathode side and electrolyte, respectively.

\subsubsection{Anode Side}

The configuration of a SOFC anode can be simply modeled as shown by the part (b) in figure 1 . The coupled electrochemical reaction and mass transfer in a composite anode are illustrated by figure 2 . The reaction processes can be summarized as: (1) transport of reactant $\left(\mathrm{H}_{2}\right)$ to the reaction sites through the pores of the anode and transport of $\mathrm{O}^{2-}$ from the electrolyte to the reaction sites through the ionic conducting particles, (2) electrochemical reaction of $\mathrm{H}_{2}$ and $\mathrm{O}^{2-}$ to form $\mathrm{H}_{2} \mathrm{O}$ and electrons at the active sites, (3) transport of electrons from the active sites to the current collector through the electronic conducting particles and transport of the $\mathrm{H}_{2} \mathrm{O}$ product to the anode surface via the pores of the anode. Therefore, the anode is usually formed by the mixture of ionic and electronic conducting materials with proper porosity present in the structure so that gases can reach the reaction sites. In the same way the configuration of the composite cathode of a SOFC consists of both electronic and ionic conducting particles, the mathematical model can be formed in a similar manner.

Charge balance in the electronic and ionic conducting particles can be written as

$$
\nabla \cdot J_{e, a}=R_{a} \text { or } \nabla \cdot J_{e, a}=A_{v} J_{n, a}
$$

and

$$
\nabla \cdot J_{i, a}=-R_{a} \text { or } \nabla \cdot J_{i, a}=-A_{v} J_{n, a}
$$

where $J_{e, a}$ and $J_{i, a}$ are the current density $\left(\mathrm{Am}^{-2}\right)$ in the electronic and ionic conducting particles. $R_{a}$ is the 
volumetric current density produced in the anode due to hydrogen oxidation reaction $\left(\mathrm{A} \mathrm{m}^{-3}\right.$ ). $A_{v}$ is the electrochemically active surface area per unit volume of the porous anode $\left(\mathrm{m}^{2} \mathrm{~m}^{-3}\right.$ or $\left.\mathrm{m}^{-1}\right)$ and $J_{n, a}$ is the transferred current per unit area of reactive surface $\left(\mathrm{A} \mathrm{m}^{-2}\right)$. The term $A_{v}$ can be calculated with the method based on the particle coordinate number in binary random packing of spheres proposed by Costamagna et al [16], given as

$A_{v}=\pi \sin ^{2} \theta r_{e l}^{2} n_{t} n_{e l} n_{i o} \frac{Z_{e l} Z_{i o}}{Z} p_{e l} p_{i o}$

where $\theta$ is the contact angle between electron and ion conducting particles, $r_{e l}$ is the radius of the electron conducting particles, $n_{t}$ is the total number of particles per unit volume, $n_{e l}$ and $n_{i o}$ are the number fraction of electron and ion conducting particles, $Z_{e l}$ and $Z_{i o}$ are the coordination number of electron and ion conducting particles. $Z$ is the total average particle coordination number in the electrode which is equal to 6 [16] and $p_{e l}$ and $p_{i o}$ are the probabilities for an electron and an ion conducting particle to belong to connecting ends of the composite. All previous mentioned parameters required to calculate $A_{v}[16,17]$ are related to each other as shown here,

$$
\begin{array}{ll}
n_{e l}=\frac{\varphi}{\left[\varphi+\left((1-\varphi) /\left(r_{i o} / r_{e l}\right)^{3}\right)\right]} \text { and } n_{i o}=1-n_{e l} \\
Z_{e l}=3+\frac{Z-3}{\left[n_{e l}+\left(1-n_{e l}\right)\left(r_{i o} / r_{e l}\right)^{2}\right]} \text { and } & Z_{i o}=3+\frac{(Z-3)\left(r_{i o} / r_{e l}\right)^{2}}{\left[n_{e l}+\left(1-n_{e l}\right)\left(r_{i o} / r_{e l}\right)^{2}\right]} \\
p_{e l}=\left[1-4-Z_{e l-e l} 2.5\right]^{0.4} \text { and } & p_{i o}=\left[1-4-Z_{i o-i o} 2.5\right]^{0.4}
\end{array}
$$

where $\varphi$ is a volume fraction of the electron conducing particle in an electrode, $Z_{e l-e l}$ represents the average coordination number between electronic particles and $Z_{\text {io-io }}$ represents the average coordination number between ionic particles [16,17],

$$
Z_{e l-e l}=\frac{n_{e l} Z_{e l}^{2}}{Z} \text { and } \quad Z_{i o-i o}=\frac{n_{i o} Z_{i o}^{2}}{Z}
$$

The total number of particles per unit volume $\left(n_{t}\right)$, depending on porosity $\varepsilon$ and particle radius sizes (radii $r_{e l}$ and $r_{i o}$ for electronic and ionic conducting particles, respectively) can be determined according to Eq. (8) [16],

$$
n_{t}=\frac{1-\varepsilon}{(4 / 3) \pi r_{e l}^{3}\left[n_{e l}+\left(1-n_{e l}\right)\left(r_{i o} / r_{e l}\right)^{3}\right]}
$$

According to Butler -Volmer equation [18], the volumetric current density produced in the anode, $R_{a}$ and the transfer current density $J_{n, a}$ can be determined from : 
$R_{a}=A_{v} J_{0, r e f}^{H_{2}}\left\{\left(\frac{c_{H 2}}{c_{H 2, r e f}}\right)^{\gamma_{H 2}}\left(\exp \left(\frac{\alpha z F \eta_{a}}{R T}\right)-\exp \left(-\frac{(1-\alpha) z F \eta_{a}}{R T}\right)\right)\right\}$

and

$$
J_{n, a}=J_{O, a}^{r e f}\left\{\frac{P_{H_{2}}}{P_{H_{2}}^{O}} \exp \left(\frac{\alpha z F \eta_{a}}{R T}\right)-\frac{P_{H_{2} O}}{P_{H_{2} O}^{O}} \exp \left(\frac{-(1-\alpha) z F \eta_{a}}{R T}\right)\right\}
$$

where $J_{0, r e f}$ is the reference exchange current densities at the reference concentration $c_{r e f}-$ i.e. for $\mathrm{H}_{2}$ oxidation $J_{0, \text { ref }}^{H_{2}}$ is $1320 \mathrm{~A} \mathrm{~m}^{-2}$ for $\mathrm{O}_{2}$ reduction $J_{0, \text { ref }}^{O_{2}}$ is $400 \mathrm{~A} \mathrm{~m}^{-2}$ [19]. $J_{0}^{\text {ref }}$ is the reference exchange current density of the electrode - i.e. for an anode, $J_{0, a}^{r e f}$ is $4000 \mathrm{~A} \mathrm{~m}^{-2}$ and for a cathode, $J_{0, c}^{r e f}$ is $1300 \mathrm{~A} \mathrm{~m}^{-2}$ [19]. $P_{\mathrm{H}_{2} \mathrm{O}}$ and $P_{\mathrm{H}_{2} \mathrm{O}}^{\mathrm{O}}$ are respectively the partial pressures of $\mathrm{H}_{2} \mathrm{O}$ within the porous anode and at the anode surface. Similarly, $P_{H_{2}}$ and $P_{H_{2}}^{0}$ are the partial pressures of $\mathrm{H}_{2}$ within the porous anode and at the anode surface. The parameter $\alpha$ is the charge transfer coefficient which is 0.5 [24], $z$ is the number of charges involved in a reaction. $R$ is universal gas constant equal to $8.314 \mathrm{Jmol}^{-1} \mathrm{~K}^{-1}$ and $T$ is cell operating temperature (K). The overpotential at the anode $\eta_{a}[16,24]$ is

$\eta_{a}=\left(\phi_{e, a}^{0}-\phi_{i, a}^{0}\right)-\left(\phi_{e, a}-\phi_{i, a}\right)$

where $\phi_{i, a}$ and $\phi_{e, a}$ denote the ionic and electronic potentials. The superscript 0 represents the equilibrium state. The electronic and ionic potentials can be obtained from applying Ohm's law as Eq. (12).

$\nabla \cdot \phi_{e, a}=\rho_{e, a}^{e f f} J_{e, a}$ and $\nabla \cdot \phi_{i, a}=\rho_{i, a}^{e f f} J_{i, a}$

where $\rho^{\text {eff }}[19]$ is the effective resistivity $(\Omega \mathrm{m})$ and $J$ is the current density. The subscripts $i$ and $e$ represent ionic and electronic conductors, respectively. $\rho^{\text {eff }}$ can be determined by Eq. (13) [19].

$\rho_{e, a}^{e f f}=\frac{\tau}{\varphi(1-\varepsilon) \sigma_{e, a}}$ and $\quad \rho_{i, a}^{e f f}=\frac{\tau}{(1-\varphi)(1-\varepsilon) \sigma_{i, a}}$

where $\sigma_{e}$ is the conductivity of electronic conductor -i.e. for an anode, $\sigma_{e, a}$ is $2 \times 10^{6} \mathrm{Sm}^{-1}[16,24]$ and for a cathode, $\sigma_{e, c}$ is $1 \times 10^{4} \mathrm{Sm}^{-1}$ [25]. $\sigma_{i}$ is the ionic conductivity -i.e. for an anode $\sigma_{i, a}$ is $3.44 \times 10^{4} \exp (-10300 / T)$, for a cathode, $\sigma_{i, c}$ is also $3.44 \times 10^{4} \exp (-10300 / T)$ and $\tau$ is the electrode tortuosity. $\tau$ is found by applying a geometrical model for tortuosity of streamline in porous media when the particles have a spherical shape [26]. The relevant equations for the tortuosity calculation are shown in an appendix A. 
From Eq. (11), Eq. (12) and Eq. (13), the first and second derivatives of $\eta_{a}$ are,

$$
\begin{aligned}
& \frac{d \eta_{a}}{d x}=\rho_{i, a}^{e f f} J_{i, a}-\rho_{e, a}^{e f f} J_{e, a} \\
& \frac{d^{2} \eta_{a}}{d x^{2}}=\rho_{i, a}^{e f f} \frac{d J_{i, a}}{d x}-\rho_{e, a}^{e f f} \frac{d J_{e, a}}{d x}=A_{v} J_{n, a}\left(\rho_{i, a}^{e f f}+\rho_{e, a}^{e f f}\right) \\
& \frac{d^{2} \eta_{a}}{d x^{2}}=A_{v} J_{O, a}^{r e f}\left(\rho_{i, a}^{e f f}+\rho_{e, a}^{e f f}\right)\left\{\frac{P_{H_{2}}}{P_{H_{2}}^{O}} \exp \left(\frac{\alpha z F \eta_{a}}{R T}\right)-\frac{P_{H_{2} O}}{P_{H_{2} O}^{O}} \exp \left(-\frac{(1-\alpha) Z F \eta_{a}}{R T}\right)\right\}
\end{aligned}
$$

The term $A_{v}$ in Eq. (16) relates to the electrode porosity $(\varepsilon)$, the particle radius $\left(r_{i o}, r_{e l}\right)$ and a volume fraction of the electron conducing particle in an electrode $(\varphi)$. At the anode surface, $J_{i, a}=0$ and $J_{e, a}=J_{\text {total }}$. At the electrolyte interface, $J_{i, a}=J_{\text {total }}$ and $J_{e, a}=0$.

Therefore, two boundary conditions for the second order differential Eq. (16) to determine the overpotential at the anode $\eta_{\mathrm{a}}$, can be written as shown in Eq. (17),

$$
x=x_{a}=0,\left.\frac{d \eta_{a}}{d x}\right|_{x=0}=-\rho_{e, a}^{e f f} J_{\text {total }} \quad \text { and } \quad x=x_{a}=t_{a n},\left.\frac{d \eta_{a}}{d x}\right|_{x=t_{a n}}=\quad \rho_{i, a}^{e f f} J_{\text {total }}
$$

The positions of $x=x_{a}=0$ and $x=x_{a}=t_{a n}$ are shown by part (b) in figure 1.

While the electrochemical reactions due to mass transport occur in SOFC electrode. Mass transport through porous medium can be determined using concepts described in [27]. For a single component, the mass transport equation can be written as

$$
\frac{\varepsilon}{R T} \frac{\partial\left(y_{i} P\right)}{\partial t}=-\nabla \cdot N_{i}+R_{i}\left(\operatorname{mol~m} \mathrm{m}^{-3}\right)
$$

where $\varepsilon$ and $N_{i}$ represent the porosity and the rate of mass transport (or denotes as the molar flux of each species, mol m${ }^{-2} \mathrm{~s}^{-1}$ ), respectively, into porous media. $R_{i}$ is the rate of reaction inside the porous medium. The term on the left-hand side is valid when unsteady state is approached. The first and second terms on the right-hand side represent the diffusion rate and the rate of reaction inside the porous medium. It was assumed earlier that the diffusion process is at steady state and that the electrochemical reactions take place at the three phase boundary (TPB) inside the electrode. Therefore, within the anode, the first and second term on the right-hand side is significant, Eq. (18), therefore, becomes 
The rate of mass transport, $N_{i}$, generally depends on the operating conditions (reactant concentration, temperature and pressure) and the microstructure of material (porosity, tortuosity and pore size). Three models were used to develop expressions for $N_{i}$ : Fick's, the Dusty-Gas and the Stefan-Maxwell models. Only, Fick's and Dusty-Gas use to describe the transport of components within porous media but the Stefan-Maxwell Model (SMM) is a well-known mass transport model applied to nonporous medium [21].

Normally, to describe the transport of components within porous media the simplest is using Fick's model that takes into account diffusion and convection transport. The convection transport term is described by the Darcy equation that relates with the permeability, viscosity of fluid, total pressure and pressure gradient [21]. However, it is assumed that the total pressure change within the pore is insignificant $(d P / d x \approx 0)$. Thus, only the diffusion transport is necessary to determine the rate of mass transport by Fick's model. Another model to describe the transport of components within porous media is Dusty-Gas Model (DGM) that also includes the permeation flux and is applied to take into account the effect of total pressure gradient on mass transport. However, it is assumed in this study that the total pressure is uniform over the entire depth of the porous electrode. Thus, the definite total pressure gradient term can be ignored. Consequently, only the diffusion flux is addressed for the DGM model. So, which means the primary mode of species transport in the porous electrode is by diffusion is considered in this work.

The mass transfer process inside the porous electrode is by means of diffusion was also selected by the reason that describe above and by the recommendation in the literatures [21-23]. Suwanwarangkul et al [21] were concluded that the Dusty-Gas Model (DGM) is the most appropriate model to simulate gas transport phenomena inside a SOFC electrode. The mass flux of species i can be determined by Dusty Gas Model (DGM) that is considered both Knudsen diffusion and Molecular diffusion. The DGM is the most suitable model for the $\mathrm{H}_{2}-\mathrm{H}_{2} \mathrm{O}$ system [21]. Suwanwarangkul et al is also demonstrated that only the DGM is recommended for a multi component system. This is because it takes into account Knudsen diffusion effect as well as Graham's law of diffusion to calculate the flux ratios. Then the Dusty - Gas model (DGM) was used to developed the expressions for $\mathrm{N}_{\mathrm{i}}$ in this work. The electrochemical reactions due to mass transport occur in SOFC electrode that represents by the term $R_{i}$ or $R_{i}$ is the rate of electrochemical reaction per unit volume of the porous electrode ( $\left.m o l \mathrm{~m}^{-3} \mathrm{~s}^{-1}\right)$. The electrochemical reaction rate of $\mathrm{H}_{2} \mathrm{O}$ and $\mathrm{H}_{2}$ can be expressed by Faraday's Law as :

$$
\begin{aligned}
& R_{\mathrm{H}_{2}}=\left(-A_{v} J_{n, a}\right) /(2 F) \\
& R_{\mathrm{H}_{2} \mathrm{O}}=\left(A_{v} J_{n, a}\right) /(2 F)
\end{aligned}
$$


The DGM includes the Stefan-Maxwell formulation and takes into account Knudsen diffusion and Molecular diffusion [21]. It is assumed from this model that pore walls consist of giant molecules ('dust') uniformly distributed in space. These dust molecules are considered to be a dummy, or pseudo, species in the mixture. The general form of the DGM is shown in Eq. (22):

$$
\frac{N_{i}}{D_{i, k}^{e f f}}+\sum_{j=1, j \neq i}^{n} \frac{y_{j} N_{i-} y_{i} N_{j}}{D_{i j}^{e f f}}=-\frac{1}{R T}\left(P \frac{d y_{i}}{d x}+y_{i} \frac{d P}{d x}\left(1+\frac{B_{0} P}{D_{i, k}^{e f f} \mu}\right)\right)
$$

where $\mathrm{x}$ is a vertical direction that shown in figure 1 (b) and (c), $y_{i}$ and $y_{j}$ is the mole fraction of species $\mathrm{i}$ and $\mathrm{j}$.

From the DGM that is considered both Knudsen diffusion and Molecular diffusion, so diffusion process within a pore can be typically divided into two diffusion mechanisms: Molecular diffusion and Knudsen diffusion. Molecular diffusion is dominant for large pore sizes and high system pressures while Knudsen diffusion becomes significant when the mean-free path of the molecular species is much larger than the pore size. Therefore the effective diffusivity of species $\mathrm{i},\left(D_{i}^{e f f}\right)$ can be written by combining the effective molecular diffusion ( $D_{i m}^{\text {eff }}$ ) and effective Knudsen diffusion ( $D_{i, k}^{\text {eff }}$ ) coefficients as follows Bosanquet formula [28]:

$D_{i}^{e f f}=\left(\frac{1}{D_{i m}^{e f f}}+\frac{1}{D_{i, k}^{e f f}}\right)^{-1}$

$D_{i m}^{e f f}$ and $D_{i, k}^{e f f}$ depend on the microstructure of the porous electrode (porosity, particle size and tortuosity) and on the operating conditions (temperature and pressure). The calculation of theses parameters are described in $[22,29]$. It is noted that $D_{i}^{e f f}$ given in Eq. (23) is derived from the assumption of equimolar counter diffusion of reactant and product species.

For binary component systems of hydrogen and water vapor or $\mathrm{H}_{2}(1)-\mathrm{H}_{2} \mathrm{O}(2)$ in the anode, the effective diffusion for binary systems $\left(D_{i, B}^{e f f}\right)$ becomes :

$$
D_{i, B}^{e f f}=\left(\frac{1}{D_{i j}^{e f f}}+\frac{1}{D_{i, k}^{e f f}}\right)^{-1}=\left(\frac{1}{D_{12}^{e f f}}+\frac{1}{D_{1, k}^{e f f}}\right)^{-1}
$$

The Knudsen diffusion coefficient $\left(D_{i, k}\right)$ and effective Knudsen diffusion coefficient ( $D_{i, k}^{e f f}$ ) for each gas specie [28] can be calculated by Eqs. (25) and (26). 


$$
\begin{aligned}
D_{i, k} & =\frac{2}{3} \vec{r} \sqrt{\frac{8 R T}{\pi M_{i}}}=97.0 \vec{r} \sqrt{\frac{T}{M_{i}}} \\
D_{i, k}^{e f f} & =\left(\frac{\varepsilon}{\tau}\right) D_{i, k}
\end{aligned}
$$

The binary diffusion coefficient is calculated using the Chapman-Enskog equation [28].

$$
D_{i j}=0.0018583\left(\frac{T^{3 / 2}}{p \sigma_{i j}^{2} \Omega_{D_{i j}}}\right)\left(\frac{1}{M_{i}}+\frac{1}{M_{j}}\right)^{1 / 2}
$$

where $\sigma_{i j}=\left(\sigma_{i}+\sigma_{j}\right) / 2$ is the collision diameter (in $A$ ), $\mathrm{p}$ is total pressure (in atm), $M_{i}$ and $M_{j}$ are molecular weight of species i and j, $\Omega_{D_{i j}}$ is the collision integral based on the Lennard - Jones potential [28], which can be obtained from Eq. (28).

$$
\Omega_{D i j}=\frac{1.06036}{\left(\frac{k T}{\varepsilon_{i j}}\right)^{0.15610}}+\frac{0.19300}{\exp \left(0.47635 \times\left(\frac{k T}{\varepsilon_{i j}}\right)\right)}+\frac{1.03587}{\exp \left(1.52996 \times\left(\frac{k T}{\varepsilon_{i j}}\right)\right)}+\frac{1.76474}{\exp \left(3.89411 \times\left(\frac{k T}{\varepsilon_{i j}}\right)\right)}
$$

where $k$ is the Boltzmann constant which is equal to $1.38066 \times 10^{23} \mathrm{~J} \mathrm{~K}^{-1}$ and $\varepsilon_{i j}$ is the characteristic Lennard Jones energy given by $\varepsilon_{i j}=\left(\varepsilon_{i} \varepsilon_{j}\right)^{1 / 2}$. The parameters used for calculation of $D_{i j}$ listed in the table 1 [30].

Similar to the effective Knudsen diffusion coefficient, the effective binary diffusion coefficient through the porous electrode can be calculated from Eq. (29).

$$
D_{i j}^{e f f}=\left(\frac{\varepsilon}{\tau}\right) D_{i j}
$$

Consider again on Eq. (22) that shown above, the second term on the right-hand side of Eq. (22) is called the permeation flux and is applied to take into account the effect of total pressure gradient on mass transport. However, it is assumed in this study that the total pressure is uniform over the entire depth of the porous anode. Thus, the definite total pressure gradient term can be ignored. Consequently, only the diffusion flux is addressed Eq. (22) reduces to:

$$
\frac{N_{i}}{D_{i, k}^{e f f}}+\sum_{j=1, j \neq i}^{n} \frac{y_{j} N_{i}-y_{i} N_{j}}{D_{i j}^{e f f}}=-\frac{P}{R T} \frac{d y_{i}}{d x}
$$

For diffusion with heterogeneous chemical reaction, the flux ratios are governed by reaction stoichiometry. Summing Eq. (30) over the $\mathrm{n}$ species leads to the Graham's law of diffusion in gaseous mixtures [27]. 


$$
\sum_{i=1}^{n} N_{i} \sqrt{M_{i}}=0
$$

where $\mathrm{M}_{\mathrm{i}}$ is the molecular weight of component $\mathrm{i}$. For two binary component systems of hydrogen and water vapor or $\left(\mathrm{H}_{2}(1)-\mathrm{H}_{2} \mathrm{O}(2)\right.$ in the anode, so Eq. (30) becomes :

$$
\frac{N_{1}}{D_{i, k}^{e f f}}+\frac{y_{2} N_{1-y_{1}} N_{2}}{D_{12}^{e f f}}=-\frac{P}{R T} \frac{d y_{1}}{d x}
$$

Rearranging Eq. (32) gives

$$
N_{1}\left(\frac{1}{D_{i, k}^{e f f}}+\frac{y_{2}-y_{1} N_{2} / N_{1}}{D_{12}^{e f f}}\right)=-\frac{P}{R T} \frac{d y_{1}}{d x}
$$

Because $y_{2}=1-y_{1}$ and $N_{2} / N_{1}=-\sqrt{M_{1} / M_{2}}$ (Graham's law), $N_{l}$ can be written as follow :

$$
N_{1}=-\frac{P}{R T}\left(\frac{1-\alpha y_{1}}{D_{12}^{e f f}}+\frac{1}{D_{1, k}^{e f f}}\right)^{-1} \frac{d y_{1}}{d x}
$$

where $\alpha=1-\sqrt{M_{1} / M_{2}}$, the parameters $M_{1}$, and $M_{2}$ are the molecular weight of species 1 and 2, respectively. For two binary component systems of hydrogen and water vapor or $\left(\mathrm{H}_{2}(1)-\mathrm{H}_{2} \mathrm{O}(2)\right.$ in the anode, so Eq. (34) becomes

$N_{H_{2}}=-\frac{P}{R T}\left(\frac{1-\alpha y_{H_{2}}}{D_{\mathrm{H}_{2} \mathrm{O}-\mathrm{H}_{2}}^{e f f}}+\frac{1}{D_{\mathrm{H}_{2}, k}^{e f f}}\right)^{-1} \frac{d y_{H_{2}}}{d x}$

where $\alpha=1-\sqrt{M_{H_{2}} / M_{H_{2} O}}$. The parameters $M_{H_{2}}$, and $M_{H_{2} \mathrm{O}}$ are the molecular weight of $\mathrm{H}_{2}$ and $\mathrm{H}_{2} \mathrm{O}$, respectively. The $D_{\mathrm{H}_{2}, k}^{e f f}$ and $D_{\mathrm{H}_{2} \mathrm{O}-\mathrm{H}_{2}}^{\text {eff }}$ are the effective Knudsen diffusion coefficient of $\mathrm{H}_{2}$ and the effective binary diffusion coefficient of $\mathrm{H}_{2}-\mathrm{H}_{2} \mathrm{O}[29]$ respectively.

By substituting Eq. (35) into Eq. (19), the governing equation of $\mathrm{H}_{2}$ concentration becomes

$$
\frac{d^{2} y_{H_{2}}}{d x^{2}}+\frac{\alpha}{D_{\mathrm{H}_{2} \mathrm{O}-\mathrm{H}_{2}}^{\text {eff }}}\left(\frac{1}{D_{\mathrm{H}_{2}, k}^{\text {eff }}}+\frac{1-\alpha y_{\mathrm{H}_{2}}}{D_{\mathrm{H}_{2} \mathrm{O}-\mathrm{H}_{2}}^{\text {eff }}}\right)^{-1}\left(\frac{d y_{\mathrm{H}_{2}}}{d x}\right)^{2}-\frac{A_{v} J_{n, a} R T}{2 F P}\left(\frac{1}{D_{\mathrm{H}_{2, k}}^{\text {eff }}}+\frac{1-\alpha y_{H_{2}}}{D_{\mathrm{H}_{2} \mathrm{O}-\mathrm{H}_{2}}^{\text {eff }}}\right)=0
$$


Equation (36) is in the form of an ordinary differential equation, which can be solved by involving the following initial conditions. In Eqs. (37) and (38), Dalton's law of an ideal gas, $y_{H_{2}}=P_{H_{2}} / P_{H_{2}}^{O}$ and the initial conditions are following as:

IC.1 : $\left.y_{H_{2}}\right|_{x=0}=y_{H_{2}, \text { bulk }}$

IC.2: $\left.\frac{d y_{\mathrm{H}_{2}}}{d x}\right|_{x=0}=\frac{-R T J_{\text {total }}}{2 F P}\left(\frac{1-\alpha y_{H_{2}, \text { bulk }}}{D_{\mathrm{H}_{2} \mathrm{O}-\mathrm{H}_{2}}^{e f}}+\frac{1}{D_{\mathrm{H}_{2, k}}^{e f f}}\right)$

It can be obtained the mole fraction of $\mathrm{H}_{2} \mathrm{O}$ as :

$y_{\mathrm{H}_{2} \mathrm{O}}=1-y_{\mathrm{H}_{2}}$.

In the above mentioned equations, the gas molar fraction, gas diffusion coefficients, current density, reaction rate, and the overpotential are dependent of depth in the vertical direction (x). Due to the complicated phenomena involved, an iterative scheme is used to solve the non-linear equations. The iterative computation is successful if a convergence is obtained. Therefore, the differential equation was solved numerically in MATLAB [31]. After obtaining the distributions of species concentration, current densities, and overpotentials, the overall electrode overpotential can be determined [16].

$\eta_{t, a}=\left(\phi_{e, a}^{0}-\phi_{i, a}^{0}\right)-\left(\phi_{e, a(x=0)}-\phi_{i, a\left(x=t_{a n}\right)}\right)$

\subsubsection{Cathode Side}

The configuration of a SOFC cathode can be simply modeled similar to anode that shown by the part (c) in figure 1 by instead the electronic conducting particle with LSM (Strontium - doped Lanthanum Manganite) and the ionic conducting particle with YSZ (Yttria - Stabilized Zirconia). The reaction processes can be summarized as at the same time of the reaction at the anode side. The oxidant (oxygen) is introduced at the cathode side where it diffuses through the porous cathode structure and reacts with electrons from the external circuit to produce $\mathrm{O}^{2-}$ at the vicinity of active sites. Then, they are transferred to the anode side through the electrolyte. Similar to the anode, the coupled electrochemical reactions and transport behaviors at the cathode can be determined from 


$$
\begin{aligned}
& \frac{d^{2} \eta_{c}}{d x^{2}}=\rho_{i, c}^{e f f} \frac{d J_{i, c}}{d x}-\rho_{e, c}^{\text {eff }} \frac{d J_{e, c}}{d x}=A_{v} J_{n, c}\left(\rho_{i, c}^{e f f}+\rho_{e, c}^{e f f}\right) \\
& \frac{d^{2} \eta_{c}}{d x^{2}}=A_{v} J_{0, c}^{r e f}\left(\rho_{i, c}^{e f f}+\rho_{e, c}^{e f f}\right)\left\{\frac{P_{O_{2}}}{P_{O_{2}}^{0}} \exp \left(\frac{\alpha z F \eta_{c}}{R T}\right)-\exp \left(-\frac{(1-\alpha) Z F \eta_{c}}{R T}\right)\right\}
\end{aligned}
$$

and

$$
\nabla \cdot J_{e, c}=-A_{v} J_{n, c}=-A_{v} J_{0, c}^{r e f}\left\{\frac{P_{O_{2}}}{P_{O_{2}}^{0}} \exp \left(\frac{\alpha z F \eta_{c}}{R T}\right)-\exp \left(-\frac{(1-\alpha) Z F \eta_{c}}{R T}\right)\right\}
$$

$A_{V}$ can be calculated with the method based on the particle coordinate number in binary random packing of spheres proposed by Costamagna et al. [16] that shown in above section similar to the anode part.

Similar to the anode, the boundary conditions for Eqs. (42) and (43) are:

$$
x=0 ; J_{e, c}=J_{\text {total }} \quad \text { and } \quad \frac{d \eta_{c}}{d x}=-\rho_{e, c}^{\text {eff }} J_{\text {total }} \text { and } x=t_{c a t} ; J_{i, c}=J_{\text {total }} \text { and } \frac{d \eta_{c}}{d x}=\rho_{i, c}^{\text {eff }} J_{\text {total }}
$$

The positions of $x=x_{c}=0$ and $x=x_{c}=t_{c a t}$ are shown by part (c) in figure 1.

Because the flux of nitrogen is not participate in the electrochemical reaction on the cathode side, that only the oxygen to participate in the electrochemical at the cathode. The concentration of $\mathrm{O}_{2}$ can be determined by self-diffusion mechanism [32], and can be expressed below.

About Cathode self-diffusion on the cathode side,

$$
\begin{gathered}
J_{O_{2}}=-D_{c} \nabla C_{O_{2}}+y_{O_{2}} \delta_{O_{2}} J_{O_{2}} \\
\delta_{O_{2}}=\frac{D_{O_{2}, k(e f f)}}{D_{O_{2}, k(e f f)}+D_{O_{2}-N_{2}(e f f)}}
\end{gathered}
$$

where $J_{O 2}$ is oxygen mol flux $\left(\mathrm{mol} \mathrm{s}^{-1}\right), C_{O 2}$ is $\mathrm{O}_{2}$ concentration $\left(\mathrm{mol} \mathrm{m}^{-3}\right)$ and $y_{\mathrm{O}_{2}}$ is $\mathrm{O}_{2}$ mole fraction.

For one - dimensional diffusion,

$$
J_{O_{2}}=-D_{O_{2}(e f f)} \frac{d C_{O_{2}}}{d x}+y_{O_{2}} \delta_{O_{2}} J_{O_{2}}
$$

Because $J_{O_{2}}=-J_{e, c} / 4 F$ and $d C_{O_{2}}=d p_{O_{2}} / R T$, so 
$\frac{d P_{O_{2}}}{P_{c}-\delta_{O_{2}} P_{O_{2}}}=\frac{R T J_{e, c}}{4 F D_{O_{2}(e f f)} P_{c}} d x$

Integrating this equation with the boundary condition $P_{O_{2}}=P_{O_{2}}^{0}$ at the cathode surface yields $\left(\mathrm{O}_{2}\right.$ pressure at inlet condition)

$\ln \left(\frac{P_{c} / \delta_{O_{2}}-P_{O_{2}}}{P_{c} / \delta_{O_{2}}-P_{O_{2}}^{0}}\right)=\frac{\delta_{O_{2}} R T J_{e, c}}{4 F D_{O_{2}(e f f)} P_{c}} t_{c a t}$

Therefore, the partial pressure of oxygen at the cathode reaction sites is

$P_{O_{2}}=\frac{P_{c}}{\delta_{O_{2}}}-\left(\frac{P_{c}}{\delta_{O_{2}}}-P_{O_{2}}^{0}\right) \exp \left(\frac{\delta_{O_{2}} R T J_{e, c} t_{c a t}}{4 F D_{c(e f f)} P_{c}}\right)$

where

$\frac{1}{D_{O_{2}(\text { eff })}}=\frac{\tau_{c a t}}{\varepsilon_{c a t}}\left(\frac{1}{D_{O_{2}, k}}+\frac{1}{D_{O_{2}-N_{2}}}\right)$

and

$D_{c, e f f}=D_{O_{2}(e f f)}$

The differential equation of Eq. (50) is

$\frac{d P_{O_{2}}}{d x}=-\frac{R T J_{e, c}}{4 F D_{O_{2}}^{e f f} P_{C}}\left(P_{C}-\left(D_{O_{2}, k}^{e f f} /\left(D_{O_{2}, k}^{e f f}+D_{O_{2}-N_{2}}^{e f f}\right)\right) \cdot P_{O_{2}}\right)$

The boundary condition for the transporting of $\mathrm{O}_{2}$ Eq. (53) is $P_{O_{2}}=P_{O_{2}}^{0}$ at $\mathrm{x}=0$.

The cathode overpotential can be expressed as Eq. (54) [16].

$\left.\eta_{t, c}=\left(\phi_{i, c}^{0}-\phi_{e, c}^{0}\right)-\left(\phi_{i, c\left(x=t_{c a t}\right.}\right)-\phi_{e, c(x=0)}\right)$

\subsubsection{The Electrolyte}

The dense electrolyte is used to conduct $\mathrm{O}^{2-}$ from the cathode side to electrochemically react with reactant (hydrogen) at the vicinity of the anode active sites to produce $\mathrm{H}_{2} \mathrm{O}$ and electrons. These electrons flow to the cathode side via an external circuit traveling through an electrical load or resistor. It typically made from Yttria Stabilized Zirconia (YSZ). The overpotential of the dense electrolyte can be determined by Ohm's law,

$\eta_{\text {elec }}=J_{\text {total }} R_{\text {elec }} t_{\text {elec }}$

where $R_{\text {elec }}$ and $t_{\text {elec }}$ are the resistivity $(\Omega \mathrm{m})$ and thickness $(\mathrm{m})$ of the electrolyte, respectively. 


\section{Model Validation}

For validating the present model we validated our results with available experimental data [33]. By using the parameters listed in table 2 . The predicted cell performance is compared with the experimental data found in the literature [33], and is shown in figure 3. The performance of the cell is predicted when the cell is supplied with $95 \% \mathrm{H}_{2}$ and $5 \% \mathrm{H}_{2} \mathrm{O}$ as fuel, operating at a temperature and pressure of $800{ }^{\circ} \mathrm{C}$ and 1 atm, respectively. Oxygen composition in the ambient air is used as oxidant. The anode, the cathode and the electrolyte were made of Nickel - doped Yttria - Stabilized Zirconia (Ni/YSZ), Strontium - doped Lanthanum Manganite (LSM or $\mathrm{La}_{0.8} \mathrm{Sr}_{0.2} \mathrm{MnO}_{3}$ ) and Yttria - Stabilized Zirconia (YSZ), with the thickness about $1 \mathrm{~mm} ., 50 \mu \mathrm{m}$. and $10 \mu \mathrm{m}$., respectively.

It can be seen that the present model predictions agree well with the experimental results. It is worth mentioning that all the parameters used in the model validation are obtained from Rogers et al. [33] except the parameters such as particle sizes, volumetric fraction of electronic and ionic conducting particle given with the other reference that from Hussain et al. [19] due to these parameters are not showed in Roger et al's work. Moreover, the value of these parameters (particle sizes, volumetric fraction of electronic and ionic conducting particle etc.) are typically use in many literatures [16 - 20, $24-25,29,32]$. The value of tortuosity is varied to obtain the best agreement between the present model predictions and the experimental results shown in figure 3 , since the value reported by Rogers et al. [33] is unity. The typical tortuosity value for SOFC electrodes is in the range of 2-6 [34]. Hence, the tortuosity value of 2.75 used in the present model predictions is in the typical range for SOFC electrodes and provides the best agreement with the experimental results. The $\mathrm{R}^{2}$-value, an indicator between 0 and 1 , reveals how closely the predicted values correspond to the experimental data, is obtained for the present model as 0.99985 .

\section{Results and Discussion}

SOFC modeling needs a number of parameters for calculation. We considered the model at steady state condition, with an operating pressure and temperature of 1 atm and $800{ }^{\circ} \mathrm{C}$. The supplied fuel compositions are $\mathrm{H}_{2}$ and $\mathrm{H}_{2} \mathrm{O}$ and oxidize by oxygen in the air. The anode, the cathode and the electrolyte were made of Nickel doped Yttria - Stabilized Zirconia (Ni/YSZ), Strontium - doped Lanthanum Manganite (LSM or $\mathrm{La}_{0.8} \mathrm{Sr}_{0.2} \mathrm{MnO}_{3}$ ) and Yttria - Stabilized Zirconia (YSZ). The dimension of cell components and standard 
parameters used in calculations are given in table 3 . The electrode porosity and tortuosity are estimated by the equations in an appendix A [26].

This model was employed to gain understanding of the coupled mass transfer and electrochemical phenomena in the electrodes of the SOFC. The present study reveals the working mechanisms of SOFC at the micro - scale level, while demonstrating the use of microstructure effect to enhance the SOFC performance and the micro characteristics of the electrodes are included into the model. The predicted cell performances are showed as the cell overpotentials at various operating and design conditions. Moreover, parametric analyses were performed to investigate the effects of operating parameters on SOFC performance. At present, the most favorable anode - supported configuration with thick anode and thin cathode/electrolyte is considered. The fuel, air composition, and the model parameters from the data available in the literatures as in table 3 used in the simulation and the simulation results are shown below.

\subsection{The Effect of Electrode Microstructure on the SOFC Overpotentials}

Because one of the performance of the SOFC was known to strongly depend on the electrode properties i.e. the volume fraction of the electron conducing particle in an electrode $(\varphi)$, the particle size ratio of the ionic to electronic conducting particle of the electrode $\left(r_{i o} / r_{e l}\right)$ [35] and the electrode porosity $(\varepsilon)$. All referring parameters are related to the electrode performance for electrochemical reaction. So, in this study the microstructure parameters relation are established and used to optimize the electrode performance by the effect of electrode microstructure on the SOFC overpotentials have been investigated. Firstly, this work is considered the effect of the ratio of particle size between the ionic and electronic conducting particle of the electrode $\left(r_{i o} / r_{e l}\right)$ and the effect of the porosity $(\varepsilon)$ on the electrode performance.

Figures $4 \mathrm{a}$ and $4 \mathrm{~b}$ show the effect of the ratio of particle size between the ionic and electronic conducting particle $\left(r_{i o} / r_{e l}\right)$ on the anode overpotential $\left(\eta_{a}\right)$ and the effect of the porosity $(\varepsilon)$ on the anode overpotential $\left(\eta_{a}\right)$, respectively. For figure $4 \mathrm{a}$, in the case of to vary the particle size ratio of the ionic to electronic conducting particle of the electrode $\left(r_{i o} / r_{e l}\right)$, the operating pressure and temperature are $1 \mathrm{~atm}$ and $1073 \mathrm{~K}$. The typical operating current density of $10,000 \mathrm{Am}^{-2}$, the electrode porosity $(\varepsilon)$ or the void fraction of the electrode is equal to 0.4 , the volume fraction of electron conducting particles $(\varphi)$ of the solid part of the electrodes is equal to 0.6 . The supplied fuel compositions are $\mathrm{H}_{2}$ and $\mathrm{H}_{2} \mathrm{O}$ by 0.95 and 0.05 mole fractions respectively and oxidize by oxygen in the air by 0.21 mole fraction and 0.79 mole fraction of $\mathrm{N}_{2}$. The others standard parameters used in the calculation are given in table 3 . For figure $4 \mathrm{~b}$ in the case of to very porosity, all parameters for calculation are the 
same as figure $4 \mathrm{a}$ except that the particle size ratio of the ionic to electronic conducting particle of the electrode $\left(r_{i o} / r_{e l}\right)$ is equal to the unity. Figure $4 \mathrm{a}$, the $\mathrm{x}$ - axis represents the ratio of particle size between the ionic and electronic conducting particle $\left(r_{i o} / r_{e l}\right)$ at the anode side whereas y - axis represents anode overpotentials $\left(\eta_{a}\right)$ and figure $4 \mathrm{~b}$, the $\mathrm{x}$ - axis represents the anode porosity $(\varepsilon)$ whereas $\mathrm{y}-$ axis represents anode overpotentials $\left(\eta_{a}\right)$. Figures $5 \mathrm{a}$ and $5 \mathrm{~b}$ show the effect of the ratio of particle size between the ionic and electronic conducting particle $\left(r_{i o} / r_{e l}\right)$ on the cathode overpotential $\left(\eta_{c}\right)$ and the effect of the porosity $(\varepsilon)$ on the cathode overpotential $\left(\eta_{c}\right)$, respectively.

The following figures $5 \mathrm{a}$ and $5 \mathrm{~b}$, all the conditions and parameters for calculation are same as figures $4 \mathrm{a}$ and 4b. Also in figure 5a, $\mathrm{x}$ - axis represents the ratio of particle size between the ionic and electronic conducting particle $\left(r_{i d} / r_{e l}\right)$ at the cathode side whereas $\mathrm{y}-$ axis represents cathode overpotentials $\left(\eta_{c}\right)$ and figure $5 \mathrm{~b}$, the $\mathrm{x}-$ axis represents the cathode porosity $(\varepsilon)$ whereas y - axis represents cathode overpotentials $\left(\eta_{c}\right)$. For both anode and cathode that show in figures $4 \mathrm{a}$ and $5 \mathrm{a}$, the minimum overpotentials were found at the ratio of particle size between the ionic and electronic conducting particle $\left(r_{i o} / r_{e l}\right)$ of about 1 to 1.25 . The results agree well with the results from Costamagna et al.'s work [16]. As shown in Costamagna et al's work [16], the ratio between the particle radii is near to unity, the high performance electrode occurs at the ratio of particle size between the electronic and ionic conducting particle $\left(r_{e} / r_{i o}\right)$ between 0.8 to 1 or it means that ratio of particle size between the ionic and electronic conducting particle $\left(\mathrm{r}_{\mathrm{io}} / \mathrm{r}_{\mathrm{el}}\right)$ between 1 to 1.25 occur at the volumetric fraction of the electron conducting particle $(\varphi)$ between 0.2 to 0.65 . It should be underlined that, in general, the particles do not have an exactly spherical shape, nor is the radius exactly defined, on the contrary there is a distribution around a mean value. This can influence the percolation thresholds in a real electrode.

Similarly, the effect of electrode porosity that show in figures $4 \mathrm{~b}$ and $5 \mathrm{~b}$, the minimum overpotential is found at the porosity between 0.4 to 0.5 . Reducing porosity that means has more solid particles are available to facilitate the transport of electronic and ionic charges which can increase the cell performance. In addition with decrease porosity can increase in active surface area for electrochemical reaction. However with decrease porosity is less space available for gas transport. The combined effects for minimization of the overall result in an optimal porosity for the electrode. Because the anode in an anode - supported SOFC is thicker than the cathode so its overpotential must be higher than the cathode and the anode side has more effect on cell performance than the cathode.

The effect of volumetric fraction of the electron conducting particle $(\varphi)$ of the solid part of the electrodes on the overpotentials $\left(\eta_{a}\right)$ at various ratio of particle size between the ionic and electronic conducting particle 
$\left(r_{i d} / r_{e l}\right)$ at the anode side is shown in figure 6a. The effect of $\varphi$ was studied at the typical operating current density of $10,000 \mathrm{Am}^{-2}$.The operating pressure and temperature are $1 \mathrm{~atm}$ and $1073 \mathrm{~K}$, the electrode porosity $(\varepsilon)$ or the void fraction of the electrode is equal to 0.4. The supplied fuel compositions are $\mathrm{H}_{2}$ and $\mathrm{H}_{2} \mathrm{O}$ by 0.95 and 0.05 mole fractions respectively and oxidize by oxygen in the air by 0.21 mole fraction and 0.79 mole fraction of $\mathrm{N}_{2}$. The others standard parameters used in the calculation are given in table 3 . The effect of volumetric fraction of the electron conducting particle $(\varphi)$ of the solid part of the electrodes on the overpotentials $\left(\eta_{a}\right)$ at various porosity $(\varepsilon)$ on the anode side is shown in figure $6 \mathrm{~b}$. For figure $6 \mathrm{~b}$ in the case of to very porosity, all parameters for calculation are the same as figure $6 \mathrm{a}$ except that the particle size ratio of the ionic to electronic conducting particle of the electrode $\left(r_{i o} / r_{e l}\right)$ is equal to the unity. Figure $6 \mathrm{a}$, the $\mathrm{x}-$ axis represents the ratio of particle size between the ionic and electronic conducting particle $\left(r_{i d} / r_{e l}\right)$ at the anode side, whereas the $\mathrm{y}$-axis represents the anode overpotentials $\left(\eta_{a}\right)$. Also in figure $6 \mathrm{~b}$, the $\mathrm{x}-$ axis represents anode porosity $(\varepsilon)$ whereas $\mathrm{y}-$ axis represents anode overpotentials $\left(\eta_{a}\right)$. Both results indicate that the minimum anode overpotentials occurred at $\varphi$ which are equal to 0.5 , are found at the ratio of particle size between the ionic and electronic conducting particle $\left(r_{i d} / r_{e l}\right)$ of about 1 to 1.5 and the at the porosity $(\varepsilon)$ between 0.35 to 0.45 .

The changes in $\eta_{a}$ with $\varphi$ demonstrate the fact that the largest active area is achieved when the dimensions and volume fractions of the ion conducting and electron conducting particles are equal [16]. When $\varphi$ equals to 0.5 , the volume fraction of ion conducting particles $(1-\varphi)$ of the solid part of the electrodes becomes equal to the volume fraction of electron conducting particles $(\varphi)$ of the solid part of the electrodes resulting in the largest active area for electrochemical reaction and hence the best performance. Moreover, the effective ionic and electronic conductivities in the reaction zone layers are functions of $\varphi$. Increasing $\varphi$ beyond 0.5 increases the effective electronic conductivity but decrease the effective ionic conductivity, which results in increasing the ohmic overpotential.

\subsection{The Effect of Operating Parameters on the SOFC Overpotentials}

Figures 7 and 8 show the effect of operating temperature and the effect of operating pressure on the overpotentials $\left(\eta_{a}\right)$ at various ratio of particle size between the ionic and electronic conducting particle $\left(r_{i d} / r_{e l}\right)$ and at various porosity $(\varepsilon)$, respectively. Both results are considered at the anode side. For figure $7 \mathrm{a}$, in the case of to vary the particle size ratio of the ionic to electronic conducting particle of the electrode $\left(r_{i o} / r_{e l}\right)$, the typical operating current density of $10,000 \mathrm{Am}^{-2}$, the electrode porosity $(\varepsilon)$ or the void fraction of the electrode is equal to 0.4 , the volume fraction of electron conducting particles $(\varphi)$ of the solid part of the electrodes is equal to 0.5 . 
The supplied fuel compositions are $\mathrm{H}_{2}$ and $\mathrm{H}_{2} \mathrm{O}$ by 0.95 and 0.05 mole fractions respectively and oxidize by oxygen in the air by 0.21 mole fraction and 0.79 mole fraction of $\mathrm{N}_{2}$. The operating pressure is at 1 atm and the operating temperature is varied. The others standard parameters used in the calculation are given in table 3. For figure $8 \mathrm{a}$, all of the calculation parameters are the same as in the case of figure $7 \mathrm{a}$ except the operating temperature is at $1073 \mathrm{~K}$ and the operating pressure is varied. For figure $7 \mathrm{~b}$ in the case of to very porosity, all parameters for calculation are the same as figure $7 \mathrm{a}$ except that the particle size ratio of the ionic to electronic conducting particle of the electrode $\left(r_{i o} / r_{e l}\right)$ is equal to the unity. In the similar cased also for figure $8 \mathrm{~b}$ in the case of to very porosity, all parameters for calculation are the same as figure 8 a except that the particle size ratio of the ionic to electronic conducting particle of the electrode $\left(r_{i o} / r_{e l}\right)$ is equal to the unity.

Figures $7 \mathrm{a}$ and $8 \mathrm{a}$, the $\mathrm{x}-$ axis represents the ratio of particle size between the ionic and electronic conducting particle $\left(r_{i d} / r_{e l}\right)$, whereas the $\mathrm{y}$ - axis represents the overpotential $\left(\eta_{a}\right)$. Also, figures $7 \mathrm{~b}$ and $8 \mathrm{~b}$, the $\mathrm{x}$ - axis represents the porosity $(\varepsilon)$, whereas the $\mathrm{y}$ - axis represents the overpotential $\left(\eta_{a}\right)$. It can be seen from figure 7 that increasing the temperature can result in increasing in the reference exchange current density and the ion conductivity of electrolyte, which in turn increase the electrochemical reaction rate. In other words, cell performance increases with the increases of temperature. Increasing the temperature not only enhances the rate of electrochemical reaction at the reaction sites but also increases the electronic and ionic conductivities of the electron and ion conducting particles, respectively. Therefore, the overpotentials of electrodes and ohmic overpotentials of electrolyte decrease with increasing temperature which in turn minimizes the cell potential loss or the overpotentials and thereby enhances the cell performance. These phenomena indicate that high temperature is desirable for SOFC from the viewpoint of energy efficiency. However, high temperature limits material selection and also causes problems associated with SOFC long-term stability, such as thermal mismatch and detachment of electrode layers from the electrolyte. So, it is important to develop new materials with high ionic conductivity and high catalytic activity at intermediate temperatures and for higher performance can use the optimum relationships of electrode microstructure parameters to enhance cell performance so cells can perform at higher temperatures, or developed new materials for utilizing cells at lower temperatures.

Figure 8 shows that at the operating pressure equal to $1 \mathrm{~atm}, 3 \mathrm{~atm}$ and $5 \mathrm{~atm}$. It can be seen that at high pressure, the electrode overpotential is lower than that at low pressure. With the increase of pressure, the reactant concentration at the reaction sites increases. This in turn enhances the rate of electrochemical reaction and the rate of mass transport resulting in the minimization of electrode overpotentials, and hence better performance. However, increase in pressure creates other difficulties, such as limitation on material selection, gas sealing, and mechanical strength of the cell components [36]. 


\subsection{Gas Composition Distribution in Electrodes}

The distribution of gas composition along the electrode depth was studied at the typical operating current density of $10,000 \mathrm{Am}^{-2}$. The electrode porosity $(\varepsilon)$ or the void fraction of the electrode is equal to 0.4 , the volume fraction of electron conducting particles $(\varphi)$ of the solid part of the electrodes is equal to 0.5. The particle size ratio of the ionic to electronic conducting particle of the electrode $\left(r_{i o} / r_{e l}\right)$ is equal to the unity. The supplied fuel compositions are $\mathrm{H}_{2}$ and $\mathrm{H}_{2} \mathrm{O}$ by 0.95 and 0.05 mole fractions respectively and oxidize by oxygen in the air by 0.21 mole fraction and 0.79 mole fraction of $\mathrm{N}_{2}$. The operating pressure is at 1 atm and the operating temperature is $1073 \mathrm{~K}$. The others standard parameters used in the calculation are given in table 3 . The part (a) of figure 9 shows distribution of $\mathrm{H}_{2}$ and $\mathrm{H}_{2} \mathrm{O}$ in the anode region and also part (b) shows distribution of $\mathrm{O}_{2}$ molar fraction distribution in cathode region. Figure 9, the $\mathrm{x}$ - axis represents the anode distance whereas $\mathrm{y}-$ axis represents $\mathrm{H}_{2}$ and $\mathrm{H}_{2} \mathrm{O}$ molar fraction for part (a) of figure 9 and $\mathrm{O}_{2}$ molar fraction for part (b) of figure 9. The part (a) of figure 9 , the concentrations of $\mathrm{H}_{2}$ decreases considerably from anode surface towards the electrolyte interface and, the concentration of $\mathrm{H}_{2} \mathrm{O}$ decreases from the electrolyte interface towards the anode surface. The part (b) of figure 9 the concentrations of $\mathrm{O}_{2}$ small decreases from cathode surface towards the electrolyte interface. The part (a) of figure 9, they are indicated the importance of gas transport in the thick anode. In addition the thin cathode shows a very low mass transfer resistance as can be seen in part (b). Figure 9 shows the important characteristic on gas distribution in an anode - supported SOFC.

The model analysis shows the cell performance strongly depend on the electrode microstructure, i.e. the volumetric composition of the electrode, the dimensions of the particle both of ionic and electronic conducting particles and the void volume of the electrode. The combined microstructure effects in a monotonic can decrease in electrode overpotential and hence the better cell performance. In addition, the study results substantiate the fact that SOFC overpotential could be effectively decreased by increasing the operating temperature, as well as the operating pressure. Therefore, the concept of microscopic model SOFC is feasible and has great potential to improve the SOFC performance by simply modifying the electrode microstructures.

\section{Conclusion}

A micro - scale model of a Solid Oxide Fuel Cell (SOFC) involving the mass transfer in the electrode together with electrochemical reaction, the transport of electrons and ions in the respective electron - conducting and ion - conducting particles in the electrodes packed with spherical - shaped particles was mathematically developed. 
A theoretical model has been presented for the evaluation of the performance of an electrode formed by a mixture of electronic conducting and ionic conducting particles. The effects of micro scale electrode geometry on the cell performance were also taken into account. Parametric study according to the volumetric fraction of ionic and electronic conducting particles was conducted in order to examine the effects of operating conditions on the cell overpotentials.

The model analysis shows the cell performance strongly depend on the electrode microstructure, i.e. the volumetric composition of the electrode, the dimensions of the particle both of ionic and electronic conducting particles and the void volume of the electrode. The combined microstructure effects in a monotonic can decrease in electrode overpotential and hence the better cell performance. In addition, the study results substantiate the fact that SOFC overpotential could be effectively decreased by increasing the operating temperature, as well as the operating pressure. The present study reveals the working mechanisms of SOFC at the micro - scale level and demonstrates the promise of the use of microstructure relationships to enhance the SOFC performance by simply modifying the electrode. This paper reveals that micro-structural electrode is very promising to enhance the SOFC performance and worthy of further investigation. Aside from their electric performance, other properties associated with micro-structural should be further investigated. The model predicted results are validated with the experimental data found in the literature. A good agreement is obtained between the predicted values and the measured data.

\section{Appendices}

\section{Appendix A: Tortuosity Model}

The geometrical model for tortuosity of streamline in three dimensional porous media when the particles have the shape as spherical which used in this SOFC modeling obtained by Meijuan Yun et al. [26]. The using equations are shown below.

$\tau=\frac{\tau_{1}+\tau_{2}}{2}$

$\tau_{1}=\frac{\left[\begin{array}{c}6 \sqrt{3 p^{2}+12 p+8}-\left(3 p^{2}+12 p+4\right) \arcsin \frac{2}{\sqrt{3}(p+2)} \\ -6(p+2)^{2} \arctan \frac{-2}{\sqrt{3 p^{2}+12 p+8}}\end{array}\right]}{[8 \sqrt{3}(p+2)]}$ 


$$
\begin{aligned}
& \tau_{2}=1+\frac{\pi-2}{\frac{4 \pi}{3(1-\varepsilon)}+\left(\frac{4 \pi}{3(1-\varepsilon)}\right)^{1 / 3}-2 \times\left(\frac{4 \pi}{3(1-\varepsilon)}\right)^{2 / 3}} \\
& p=\frac{2}{3} \sqrt{\frac{\sqrt{3} \pi}{1-\varepsilon}}-2 \\
& \varepsilon=1-\frac{4 \pi}{3 \sqrt{3}(2+d / r)^{2}}
\end{aligned}
$$

where the parameter $\varepsilon$ is the porosity for the spherical particle packed electrode and $\mathrm{d}$ is the gap size between spherical particles.

\section{List of Symbols}

$A_{v} \quad$ Active surface area per unit volume $\left[\mathrm{m}^{2} \mathrm{~m}^{-3}\right.$ or $\left.\mathrm{m}^{-1}\right]$

$D_{i j} \quad$ Binary diffusion coefficient $\left[\mathrm{m}^{2} \mathrm{~s}^{-1}\right]$

$D_{i, k} \quad$ Knudsen diffusion coefficient of the species i $\left[\mathrm{m}^{2} \mathrm{~s}^{-1}\right]$

$D_{i j}^{e f f} \quad$ Effective binary diffusion coefficient $\left[\mathrm{m}^{2} \mathrm{~s}^{-1}\right]$

F Faraday's constant, $96485\left[\mathrm{C} \mathrm{mol}^{-1}\right]$

$J_{e} \quad$ Electronic current density $\left[\mathrm{A} \mathrm{m}^{-2}\right]$

$J_{i} \quad$ Ionic current density $\left[\mathrm{A} \mathrm{m}^{-2}\right]$

$J_{n} \quad$ Transfer current per unit area of reactive surface $\left[\mathrm{A} \mathrm{m}^{-2}\right]$

$J_{\text {total }} \quad$ Total current density $\left[\mathrm{A} \mathrm{m}^{-2}\right]$

$J_{\text {ref }}^{\mathrm{H}_{2}}$ Reference exchange current density for $\mathrm{H}_{2}$ oxidation [A m ${ }^{-2}$ ]

$J_{\text {ref }}^{\mathrm{O}_{2}}$ Reference exchange current density for $\mathrm{O}_{2}$ reduction $\left[\mathrm{A} \mathrm{m}^{-2}\right.$ ]

$M \quad$ Molecular weight $\left[\mathrm{kg} \mathrm{kmol}^{-1}\right]$

$n_{e l} \quad$ Number fraction of electron - conducting particle in the electrode

$n_{i o} \quad$ Number fraction of ion - conducting particle in the electrode

$n_{t} \quad$ Total number of particles in the electrode per unit volume $\left[\mathrm{m}^{-3}\right]$

$N_{i} \quad$ Molar flux of species i $\left[\mathrm{mol} \mathrm{m}^{-2} \mathrm{~s}^{-1}\right]$

$p_{e l} \quad$ Probability of percolation of electron - conducting particles in the electrode

$p_{i o} \quad$ Probability of percolation of ion - conducting particles in the electrode

$P \quad$ Pressure $[\mathrm{atm}]$ 
$P_{H_{2}}^{a} \quad$ Hydrogen partial pressure in anode

$P_{\mathrm{H}_{2} \mathrm{O}}^{a} \quad$ Water partial pressure in anode

$P_{O_{2}}^{c} \quad$ Oxygen partial pressure in cathode

$r_{e l} \quad$ Radius of electron - conducting particles in the electrode [m]

$r_{i o} \quad$ Radius of ion - conducting particles in the electrode [m]

$R \quad$ Universal gas constant, $8.314\left[\mathrm{~J} \mathrm{~mol}^{-1} \mathrm{~K}^{-1}\right]$

$R_{a} \quad$ Volumetric current density produced due to hydrogen oxidation [A $\mathrm{m}^{-3}$ ]

$R_{i} \quad$ Reaction rate $\left[\mathrm{mol} \mathrm{m} \mathrm{m}^{-3} \mathrm{~s}^{-1}\right]$

$\vec{r} \quad$ Mean value of the pore radii [m]

$t_{a n} \quad$ Anode thickness [m]

$t_{\text {cat }} \quad$ Cathode thickness [m]

$t_{\text {elec }} \quad$ Electrolyte thickness [m]

$T \quad$ Temperature [K]

$x_{a} \quad$ Anode depth [m]

$x_{c} \quad$ Cathode depth [m]

$y_{i} \quad$ Molar fraction of species i $\left[\mathrm{mol} \mathrm{mol}^{-1}\right]$

$Z \quad$ Total average particle coordination number in electrode which equal to 6

$Z_{e l} \quad$ Coordination number of electron - conducting particles in the electrode

$Z_{i o} \quad$ Coordination number of ion - conducting particles in the electrode

$\Delta G^{o} \quad$ Net standard Gibbs free energy of electrochemical reaction at 1 atm and $25^{\circ} \mathrm{C}$

$\alpha \quad$ Charge transfer coefficient

$\gamma_{H_{2}} \quad$ Reaction order for hydrogen oxidation reaction

$\gamma_{\mathrm{O}_{2}} \quad$ Reaction order for oxygen reduction reaction

$\varepsilon \quad$ Porosity

$\eta_{a} \quad$ Anode activation overpotential [volt]

$\eta_{c} \quad$ Cathode activation overpotential [volt]

$\theta \quad$ Contact angle between electron and ion - conducting particles in the electrode

$\sigma \quad$ Electronic conductivity $\left[\mathrm{S} \mathrm{m}^{-1}\right]$

$\tau \quad$ Tortuosity 
$\phi_{e} \quad$ Electronic potential [volt]

$\phi_{i} \quad$ Ionic potential [volt]

$\varphi \quad$ Volume fraction of electron conducting particles in the electrode

\section{References}

[1] S.C. Singhal, K. Kendall, High Temperature Solid Oxide Fuel Cells: Fundamentals Design and Applications, Elsevier, Oxford, 2003, pp. 18 - 19.

[2] J. Larminie, A. Dicks, Fuel Cell Systems Explained, John Wiley and Sons, Chichester, 2003, pp. 22 24.

[3] P.A. Ramakrishna, S. Yang, C.H. Sohn, J.Power Sources 2006, 158, 378.

[4] Y.H. Koh, J.J. Sun, W.Y. Choi, H.E. Kim, J.Power Sources 2006, 161, 1023.

[5] Y. Yang, G. Wang, H. Zhang, W. Xia, J.Power Sources 2007, 173, 233.

[6] J.J. Hwang, C.K. Chen, D.Y. Lai, J.Power Sources 2005, 140, 235.

[7] J.J. Hwang, C.K. Chen, D.Y. Lai, J.Power Sources 2005, 143, 75.

[8] J.P.P. Huijsmans, F.P.F. Van Berkel, G.M. Christie, J.Power Sources 1998, 71, 107.

[9] K. Choy, W. Bai, S. Charojrochkul, B.C.H. Steele, J.Power Sources 1998, 71, 361.

[10] J.M. Ralph, A.C. Schoeler, M. Krumpelt, J.Materials Science 2001, 36, 1161.

[11] B.C.H. Steele, J. Solid State Ionics 2000, 134, 3.

[12] H. Rabat, P. Brault, Fuel Cells 2008, 8, 81.

[13] D. Beckel, A. Bieberle - Hutter, A. Harvey, A. Infortuna, U.P. Muecke, M. Prestat, J.L.M. Rupp, L.J. Gauckler, J.Power Sources 2007 , 173, 325.

[14] J.D. Morse, A.F. Jankowski, International Mechanical Engineering Congress and Exposition, Nashville, Tennessee, 1999, November 15 - 20.

[15] L.R. Pederson, P. Singh, X.D. Zhou, Vacuum 2006, 80, 1066.

[16] P. Costamagna, P. Costa, V. Antonucci, Electrochimica Acta 1998, 43, 375.

[17] X.J. Chen, S.H. Chan, K.A. Khor, Electrochimica Acta 2004, 49, 1851.

[18] J. Deseure, Y. Bultel, L. Dessemond, E. Siebert, Electrochimica Acta 2005, 50, 2037.

[19] M.M. Hussain, X. Li, I. Dincer, J.Power Sources 2006, 161, 1012.

[20] M. Ni, M.K.H. Leung, D.Y.C. Leung, J.Power Sources 2007, 168, 369. 
[21] R. Suwanwarangkul, E. Croiset, M.W. Fowler, P.L. Douglas, E. Entchev, M.A. Douglas, J.Power Sources 2003, 122, 9.

[22] H. Yakabe, M. Hishinuma, M. Uratani, Y. Matsuzaki, I. Yasuda, J.Power Sources 2000, 86, 423.

[23] W. Lehnert, J. Meusinger, F. Thom, J.Power Sources 2000, 87, 57.

[24] S.H. Chan, Z.T. Xia, J.Electrochemical Society 2001, 148, A388.

[25] S.H. Chan, X.J. Chen, K.A. Khor, J.Electrochemical Society 2004, 151, A164.

[26] M. Yun, B. Yu, P. Xu and J. Wu., The Canadian Journal of Chemical Engineering 2006, 84, 301.

[27] R. Krishna, J.A. Wesselingh, Chemical Engineering Science 1997, 52 (6), 861.

[28] R.B. Bird, W.E. Stewart, E.N. Lightfoot, Transport Phenomena, John Wiley and Sons, New York, 2001, pp. 309.

[29] S.H. Chan, Z. T. Xia, J. Applied Electrochemistry 2002, 32, 339.

[30] B. Tod, J.B. Young, J.Power Sources 2002, 110, 186.

[31] A. Gilat, V. Subramaniam, Numerical Methods for Engineers and Scientists: an Introduction with Applications Using MATLAB $1^{\text {st }}$ Edition, John Wiley \& Sons, Inc, USA, 2008.

[32] S.H. Chan, K.A. Khor, Z.T. Xia , J.Power Sources 2001, 93, 130.

[33] W.A. Rogers, R.S. Gemmen, C. Johnson, M. Prinkey, M. Shahnam, Fuel Cell Sci. Eng. Technol. ASME 2003, 517.

[34] M. Iwata, T. Hikosaka, M. Morita, T. Iwanari, K. Ito, K. Onda, Y. Esaki, Y. Sakaki, S. Nagata, Solid State Ionics 2000, 132, 297.

[35] E.P. Murray, T. Tsai, S.A. Barnett, Nature 1999, 400, 469.

[36] N.Q. Minh, T. Takahashi, Science and Technology of Ceramic Fuel Cells, Elsevier Science, Amsterdam, 1995. pp. 105.

\section{Tables}

Table 1 List of Lennard-Jones potentials used in calculation (taken from Tod et al., [30])

\begin{tabular}{|cccccccc|}
\hline Gas species & $\mathrm{CH}_{4}$ & $\mathrm{H}_{2} \mathrm{O}$ & $\mathrm{CO}_{2}$ & $\mathrm{CO}$ & $\mathrm{H}_{2}$ & $\mathrm{~N}_{2}$ & $\mathrm{O}_{2}$ \\
\hline$\sigma_{i}^{a}$ & 3.758 & 2.641 & 3.941 & 3.69 & 2.827 & 3.798 & 3.467 \\
\hline$\varepsilon_{i}^{a}$ & 148.6 & 809.1 & 195.2 & 91.7 & 59.7 & 71.4 & 106.7 \\
\hline
\end{tabular}


Table 2 Parameters used for model validation (source: Rogers et al. [33])

\begin{tabular}{|c|c|}
\hline Operating temperature, $\mathrm{T}\left({ }^{\circ} \mathrm{C}\right)$ & 800 \\
\hline Total pressure, $\mathrm{P}$ (atm) & 1 \\
\hline Fuel composition, $\mathrm{x}_{\mathrm{H} 2}, \mathrm{x}_{\mathrm{H} 2 \mathrm{O}}$ & $0.95,0.05$ \\
\hline Air composition, $\mathrm{x}_{\mathrm{O} 2}, \mathrm{x}_{\mathrm{N} 2}$ & $0.21,0.79$ \\
\hline Conductivity of electronic conductor of anode, $\sigma_{\mathrm{e}, \mathrm{a}}\left(\mathrm{Sm}^{-1}\right)$ & 71428.57 \\
\hline Conductivity of electronic conductor of cathode, $\sigma_{\mathrm{e}, \mathrm{c}}\left(\mathrm{Sm}^{-1}\right)$ & 5376.34 \\
\hline Conductivity of ionic conductor of anode, $\sigma_{i, a}\left(\mathrm{Sm}^{-1}\right)$ & 0.64 \\
\hline Conductivity of ionic conductor of cathode, $\sigma_{i, c}\left(\mathrm{Sm}^{-1}\right)$ & 0.64 \\
\hline Electrolyte conductivity, $\kappa_{\text {elec }}(\mathrm{S} / \mathrm{m})$ & 0.64 \\
\hline Anode electrode layer thickness, $\mathrm{t}_{\mathrm{a}}(\mu \mathrm{m})$ & 1000.0 \\
\hline Cathode electrode layer thickness, $\mathrm{t}_{\mathrm{c}}(\mu \mathrm{m})$ & 50.0 \\
\hline Electrolyte thickness, $\mathrm{t}_{\mathrm{e}}(\mu \mathrm{m})$ & 10.0 \\
\hline Porosity of anode and cathode, $\varepsilon$ & 0.375 \\
\hline Tortuosity of anode and cathode, $\tau$ & 2.75 \\
\hline Pore radius of anode and cathode, $r_{p}(\mu \mathrm{m})$. & 0.75 \\
\hline Contact angle between $\mathrm{e}^{-}$and $\mathrm{O}^{2-}$ conducting particles, $\theta\left({ }^{\circ}\right)[19]$ & 15 \\
\hline Radius of electronic conducting particle, $\mathrm{r}_{\mathrm{el}}(\mu \mathrm{m})[19]$ & 0.1 \\
\hline Radius of ionic conducting particle, $\mathrm{r}_{\mathrm{io}}(\mu \mathrm{m})[19]$ & 0.1 \\
\hline Volume fraction of electronic conducting particle, $\varphi[19]$ & 0.5 \\
\hline Volume fraction of ionic conducting particle, $1-\varphi[19]$ & 0.5 \\
\hline Reference $\mathrm{H}_{2}$ concentration, $\mathrm{c}_{\mathrm{H} 2 \text {,ref }}\left(\mathrm{mol} \mathrm{m}^{-3}\right)$ [19] & 10.78 \\
\hline Reference $\mathrm{O}_{2}$ concentration, $\mathrm{c}_{\mathrm{O} 2 \text {,ref }}\left(\mathrm{mol} \mathrm{m}^{-3}\right)$ [19] & 2.38 \\
\hline Reference exchange current density for $\mathrm{H}_{2}$ oxidation, $\mathrm{J}_{0, \mathrm{ref}}^{\mathrm{H}_{2}}\left(\mathrm{~A} \mathrm{~m}^{-2}\right)[19]$ & 1320 \\
\hline Reference exchange current density for $\mathrm{O}_{2}$ reduction, $\mathrm{J}_{0 \text {,ref }}^{\mathrm{O}_{2}}\left(\mathrm{~A} \mathrm{~m}^{-2}\right)$ [19] & 400 \\
\hline Reaction order for $\mathrm{H}_{2}$ oxidation, $\gamma_{\mathrm{H} 2}[19]$ & 0.5 \\
\hline
\end{tabular}


Table 3 Standard parameters used in the SOFC model calculation

\begin{tabular}{|l|c|}
\hline \multicolumn{1}{|c|}{ Parameters } & Values \\
\hline Operating temperature, $\mathrm{T}\left({ }^{\circ} \mathrm{C}\right)$ & 800 \\
Operating pressure, $\mathrm{P}(\mathrm{atm})$ & $0.95,0.05$ \\
$\mathrm{H}_{2}$ and $\mathrm{H}_{2} \mathrm{O}$ in fuel mixture inlet mole fraction & $0.21,0.79$ \\
$\mathrm{O}_{2}$ and $\mathrm{N}_{2}$ in air inlet mole fraction & 2000 \\
Anode thickness, $\mathrm{t}_{\mathrm{a}}(\mu \mathrm{m})$. & 1.38 \\
Anode tortuosity, $\tau_{\mathrm{a}}$ & $($ Eq. in an appendix A) \\
Porosity of anode, $\varepsilon_{\mathrm{a}}$ & 0.4 \\
Cathode tortuosity, $\tau_{\mathrm{c}}$ & $($ Eq. in an appendix A) \\
Anode pore radius $\left(\mathrm{r}_{\mathrm{p}}\right)(\mu \mathrm{m})$. & 0.5 \\
\hline
\end{tabular}




\begin{tabular}{|c|c|}
\hline & (Eq. in an appendix A) \\
\hline Porosity of cathode, $\varepsilon_{\mathrm{c}}$ & 0.4 \\
\hline & (Eq. in an appendix A) \\
\hline Cathode pore radius, $r_{p}(\mu \mathrm{m})$. & 0.5 \\
\hline Electrolyte thickness, $\mathrm{t}_{\text {elec }}(\mu \mathrm{m})$. & 60 \\
\hline Contact angle between $\mathrm{e}^{-}$and $\mathrm{O}^{2-}$ conducting particles, $\theta\left(^{\circ}\right)[19]$ & 15 \\
\hline Radius of electronic conducting particle, $\mathrm{r}_{\mathrm{el}}(\mu \mathrm{m})[19]$ & 0.1 \\
\hline Radius of ionic conducting particle, $r_{i o}(\mu \mathrm{m})[19]$ & 0.1 \\
\hline Reference exchange current density for $\mathrm{H}_{2}$ oxidation, $\mathrm{J}_{0, \text { ref }}^{\mathrm{H}_{2}}\left(\mathrm{~A} \mathrm{~m}^{-2}\right)$ [19] & 1320 \\
\hline Reference exchange current density for $\mathrm{O}_{2}$ reduction, $\mathrm{J}_{0, \text { ref }}^{\mathrm{O}_{2}}\left(\mathrm{~A} \mathrm{~m}^{-2}\right)[19]$ & 400 \\
\hline Total average particle coordination number in electrode, Z [16] & 6 \\
\hline Charge transfer coefficient, $\alpha[24]$ & 0.5 \\
\hline Conductivity of electronic conductor of anode, $\sigma_{\mathrm{e}, \mathrm{a}}\left(\mathrm{Sm}^{-1}\right)[16]$ & $2 \mathrm{e} 6$ \\
\hline Conductivity of electronic conductor of cathode, $\sigma_{\mathrm{e}, \mathrm{c}}\left(\mathrm{Sm}^{-1}\right)[16]$ & $1 \mathrm{e} 4$ \\
\hline Conductivity of ionic conductor of anode, $\sigma_{i, a}\left(\mathrm{Sm}^{-1}\right)[16]$ & $3.44 \mathrm{e} 4 *(\exp (-10300 / \mathrm{T}))$ \\
\hline Conductivity of ionic conductor of cathode, $\sigma_{i, c}\left(\mathrm{Sm}^{-1}\right)[16]$ & $3.44 \mathrm{e} 4 *(\exp (-10300 / \mathrm{T}))$ \\
\hline Faraday constant, $\mathrm{F}\left(\mathrm{C} \mathrm{mol}^{-1}\right)[16]$ & 96485 \\
\hline
\end{tabular}

\section{Figure Caption}

Fig. 1 (a) A structure of a unit cell with multiple channels. (b) A cross sectional representation of a composite anode computational domain. (c) A cross sectional representation of a composite cathode computational domain.

Fig. 2 Schematic of a SOFC anode and electrochemical reaction at three phase boundaries (TPB).

Fig. 3 The comparison between model predictions and experimental results of Rogers et al [33].

Fig. 4 (a) The ratio of particle size between the ionic and electronic conducting particle effect on anode overpotentials. (b) Porosity effect on anode overpotentials.

Fig. 5 (a) The ratio of particle size between the ionic and electronic conducting particle effect on cathode 
overpotentials. (b) Porosity effect on cathode overpotentials.

Fig. 6 (a) The effect of volumetric fraction of the electron conducting particle on the overpotentials at various ratio of particle size between the ionic and electronic conducting particle on the anode side. (b) The effect of volumetric fraction of the electron conducting particle on the overpotentials at various porosity on the anode side.

Fig. 7 (a) The effect of operating temperature on SOFC overpotentials at various ratio of particle size between the ionic and electronic conducting particle on the anode side. (b) The effect of operating temperature on SOFC overpotentials at various porosity on the anode side.

Fig. 8 (a) The effect of operating pressure on SOFC overpotentials at various ratio of particle size between the ionic and electronic conducting particle on the anode side. (b) The effect of operating pressure on SOFC overpotentials at various porosity on the anode side.

Fig. 9 (a) $\mathrm{H}_{2}$ and $\mathrm{H}_{2} \mathrm{O}$ composition distribution along anode depth (b) $\mathrm{O}_{2}$ molar fraction distribution in cathode 